\title{
Insisting on Depression, but not Showing Symptoms: A Japanese Study of Excuse-Making
}

\author{
Itsuki Yamakawa $^{1} \&$ Shinji Sakamoto ${ }^{2}$ \\ ${ }^{1}$ Graduate School of Literature and Social Sciences, Nihon University, Tokyo, Japan \\ ${ }^{2}$ College of Humanities and Sciences, Nihon University, Tokyo, Japan \\ Correspondence: Itsuki Yamakawa, Graduate School of Literature and Social Sciences, Nihon University, \\ Sakurajosui, Setagaya, 156-8550, Japan. E-mail: yamakawa.itsuki@gmail.com
}

Received: January 27, 2015

Accepted: February 21, 2015

Online Published: May 29, 2015

doi:10.5539/ijps.v7n2p146

URL: http://dx.doi.org/10.5539/ijps.v7n2p146

\begin{abstract}
Since the late 1990s, Japanese psychiatrists have reported the appearance of a Modern Type Depression (MTD), which has different features from melancholic depression. Using a case vignette method, we looked at one of the distinctive features of MTD; that is, "insisting on depression". In particular, we examined whether the statement "I think I may have depressive disorder" can be accepted as an excuse for not fulfilling ones' duty when one does not show any symptoms of depressive disorder. Participants comprised 344 Japanese undergraduates who were presented with a short scenario describing social predicaments and who subsequently assessed the excuse value in terms of impression and behavioral reaction on the transgressor. Results showed that even though the transgressor did not show any symptoms of depressive disorder, insisting that one may have depressive disorder seemed to be accepted. Additionally, consistent with Weiner's cognitive (attribution)-emotion-action model, the more positive impressions observers have on the transgressor, the more they are motivated to react kindly to the transgressor. Some unexpected findings and limitations of the present study were discussed.
\end{abstract}

Keywords: account, attribution, depression, excuse, explanation, impression management, self-presentation, predicament

\section{Introduction}

The purpose of the present study is to examine whether, despite the excuse maker ("I") not clearly displaying any depressive symptoms, the statement "I think I may have depressive disorder" can be accepted as a reason for not fulfilling one's duty. There is a social background that makes us ask such a research question; that is, the appearance of "modern type depression (MTD)" in Japan (e.g., Kato et al., 2011; Tarumi, 2005). Having been reported since the late 1990s, the MTD has been widely noticed by not only Japanese clinicians but also by the general population, as the MTD has different features from those of the traditional and well-known type depression (i.e., melancholic depression) (Note 1). For instance, melancholic depression is likely to occur in middle age, while the MTD is likely to occur for those who are young. Although the two types have a common depressive symptom (i.e., complaining of depressed mood), the severity and contents are different, as the symptoms of MTD are relatively mild. While the main depressive symptoms of melancholic depression will be psychomotor agitation or retardation, exhaustion and blaming oneself, those of MTD will be fatigue, not feeling good enough, avoidance, and blaming others. Among the different features between the two types of depression, the most important one that delineates the confusing MTD may be insisting on "depression". Specifically, although people with melancholic depression resist accepting a diagnosis of depression, those with MTD are willing to accept and sometimes even request a diagnosis of depression. As some Japanese psychiatrists noted (e.g., Nomura, 2008; Yoshino, 2009), the label of being depressed may function as a reason to not fulfill one's duty (stated later, in detail), which may make people with MTD insist on "depression." However, such a self-presentational explanation is hypothetical and must be examined empirically. In the present study, we examine the self-presentational hypothesis in terms of self-presentation, in particular, excuse-making, which has long been studied in social psychology.

In the area of self-presentation, mental illness, as well as excuse-making, is categorized as defensive impression management, which occurs when an individual experiences or anticipates a predicament in order to restore a positive identity or to avoid negative reactions from others (Tedeschi \& Norman, 1985). Previous studies 
suggested that various psychological symptoms serve to a self-protective function (Baumgardenr, 1991; Baumgardenr, Lake, \& Arkin, 1985; B. Braginsky \& Braginsky, 1967; Jones \& Burglas, 1978; Snyder \& Smith, 1981). Regarding depressive disorder, Schouten and Handelsman (1987) investigated this from the perspective of self-handicapping. They examined the discounting effect of depression via an experimental survey with vignettes describing situations in which two protagonists: one who is depressed and the other who is non-depressed, violating social norms. They found that the target person showing symptoms of depressive disorder was seen as being less responsible for the cause of negative outcomes and less to blame. Furthermore, information about diagnosis, medication, and hospitalization did not affect these ratings more than symptom presentation alone. Thus, from their findings, it appeared that showing symptoms of depression may reduce responsibility for the negative outcome.

Based on the previous studies as mentioned above, we believe that there are two points to be considered. First, in the case of people with MTD, it is the statement they make that matters, not the symptoms they show. As stated above, people with MTD frequently show mild symptoms of depression compared to traditional depression, and the depression is not seen from the objective perspective (Matsuo, 2009; Nomura, 2008). In other words, depression for people with MTD appears to be seen with regard to the statement instead of their symptoms. Therefore, we believe it important to examine whether the statement functions as self-presentation. The other point is that Japanese psychiatrists noted that excuse-making is a form of self-presentation that people with MTD use, but that it is not self-handicapping. While self-handicapping is also categorized into protective self-presentation and its function is similar to excuse-making, the difference is with the timing of when individuals make a statement. While self-handicapping involves claiming an obstacle prior to performance (Berglas \& Jones, 1978), excuse-making is a way of coping with failure (Snyder \& Higgins, 1988); that is, it occurs after a failure. Hence, this study examined the impact of insisting on being depressed from the perspective of excuse-making, not from the perspective of self-handicapping.

Additionally, this study aimed to confirm the process of how individuals perceive and react to insisting on being depressed as an excuse. In order to accomplish this purpose, this study employed the cognitive (attribution)-emotion-action model (Weiner, 1995). This model describes the process of motivating behavior relating to the responsibility judgment. In this model, the process of judgments regarding the responsibility is divided into the following three steps. First, when people observe a person's failure, causal attribution then takes place; the observer assesses the cause within causal dimensions, specifically, controllability (Weiner, 1979). Second, depending on the result of causal reasoning, subsequent affects that arise therein are differed. Third, the prior affects decide the behavior of the observer to an observed. For example, if people observe a person's failure, and attribute the cause to uncontrollable factors, such as illness (in the first step), then positive affects, such as sympathy will arise (in the second step), which will facilitate helping behaviors to the person (in the third step). Reverse cases are also possible - if people observe a person's failure, and attribute the cause to controllable factors, such as laziness (in the first step), then negative affects, such as anger will arise (in the second step), which will make them withdraw from helping behaviors (in the third step). Thus, the excuse is thought to be attributional manipulations or impression management techniques to shift the attribution - either not to the self, or to the self but where the cause was not controllable (Weiner, 2006).

In sum, the aims of this study were to (a) examine the effect of insisting on depression as an excuse, and (b) confirm the process of evaluation of that excuse. To accomplish these goals, two vignettes describing the social predicament in different situations were prepared. In particular, the protagonist (i.e., excuse-maker) in the hypothetical vignettes did not show symptoms of depression but stated that they were depressed after a fault. After reading each vignette, participants assessed their impression on the target, a feeling towards an excuse-maker, and behavior they would deliver to the excuse-maker. Additionally, the controllability of depression was also assessed. We predicted that while there was no description about depressive symptom, only stating that one might have depressive disorder functioned as an excuse. In other words, people implying a depressive disorder would be able to maintain one's image and deter punishments.

\section{Method}

\subsection{Participants and Design}

Participants were $344(175$ men, mean age $=21.11, S D=5.51 ; 169$ women, mean age $=22.85, S D=8.52)$ Japanese undergraduates enrolled in general psychology and several other courses at four large private universities located in the east area of Japan (i.e., Kanto-area). This study was described as a survey about interpersonal impression. Participants were randomly assigned to an excuse or no excuse condition. All questionnaires were completed anonymously. It should be noted that, to examine the process of people 
evaluating the excuse via structural equation modeling in the excuse condition, we prepared 1.5 times more the number of questionnaires in the excuse condition compared to the no excuse condition.

\subsection{Materials}

Two vignettes (see Appendix) were written, referring to a previous study (Tyler \& Feldman, 2007). Both vignettes described a social predicament in which a target person failed to fulfill a promise, but the situations differed. In Vignette A, a student taking a course in college, did not complete the group homework assignment while other members did (college scenario); and, in Vignette B, a student, who worked at a part-time job, was absent from his work without notice (workplace scenario). These vignettes were divided in two parts.

The first half of each vignette was the making promise part. It briefly introduced the target person, the situation, and the scene ended with the protagonist making a promise to his friends. However, there was no description of psychosomatic symptoms suggesting depressive disorder. The second half of each vignette was the reneging part. Although the target person made a promise before, he did not fulfill his duty. Furthermore, the manipulation of the excuse was conducted in this part. In the no excuse condition, the vignettes ended with a sentence describing a situation in which the target broke his promise. On the other hand, in the excuse condition, the following sentences were added to the last part of vignette: When asked by the other members about why he had not done so, he replied, "I could not do it, I think I may have depressive disorder". The difference between the two conditions was only the presence of these sentences. Each participant received a booklet that contained all two vignettes, presented in counterbalanced order within the condition.

\subsubsection{Dependent Variables}

After each scenario, the dependent variables shown in Table 1 were presented. The dependent variables included ratings to assess the impression and feeling towards target (12 items; e.g., likeability, integrity, sympathy) and to gauge the behavior they would deliver (7 items; e.g., punishing, forgiving, blaming, commiserating) (Note 2). These items were adapted from previous studies (Pontari, Schlenker, \& Christpher, 2002; Tyler \& Feldman, 2007). The response options ranged from 1 (strongly disagree) to 5 (strongly agree). Ratings for negative contents were reverse-scored to facilitate interpretation. Hence, high scores represented positive cognition/affects or positive behavioral response. The items aggregated across both scenarios indicated acceptable internal consistency reliability for each measurement; Cronbach's alpha $=.87,95 \%$ CI [.85, .89] (impression, vignette A), alpha $=.79[.75,83]$ (behavior, vignette $\mathrm{A})$, alpha $=.85[.82, .87]$ (impression, vignette $\mathrm{B}$ ), alpha $=.78[.75, .83]$ (behavior, vignette $\mathrm{B}$ ).

\subsubsection{Uncontrollability of Depression}

After assessing dependent variables, participants were presented with a question measuring their causal attribution of uncontrollability on depressive disorder. This item was rated on a bipolar 7-point scale in the same way as the Attribution Style Questionnaire (Peterson, Semmel, Von Baeyer, Metalsky, \& Seligman, 1982) and a higher score was seen to represent people attributing depressive disorder as uncontrollable.

\subsection{Manipulation Checks}

To check the responsibility of the target, three items were provided after the first half of each vignette, because the previous study indicated that an excuse resulted in minimal differences in character ratings and negative repercussions from no excuse when the transgressor was perceived as being less responsible to the particular detrimental consequences (Tyler \& Feldman, 2007). Three items were on the basis of triangle model of responsibility (Schlenker, Britt, Pennington, Murphy, \& Doherty, 1994): “An obligation or duty the target person had to do was clear", "The target person had enough capacity to perform his obligation or duty" and "The target person personally committed his obligation or duty." A 5-point Likert scale was used to score each item, from 1 (strongly disagree) to 5 (strongly agree).

\subsection{Procedure}

Questionnaires were administered to participants during a lecture slot but they completed all measures individually and without discussion. Participants were briefly oriented to the broad study aims, but were not informed about the specific issues of interest to the experimenter. Students were then asked to complete the questionnaire on their own and to return the completed instrument at the end of the lecture slot. After collecting all questionnaires, participants were thoroughly debriefed. They were fully informed about the true nature of the experiment and received a handout, which was prepared so that they could understand the major depressive disorder correctly. 
Table 1. Items of dependent variables

\begin{tabular}{l}
\hline Impression and feelings \\
\hline A is immature \\
It is natural that A is criticized \\
A is earnest \\
I may work again with A \\
A is faithful \\
A is a weak person \\
A is a favorable person \\
I empathize with A \\
I feel sympathy for A \\
I feel anger for A \\
A is incompetent \\
A is reliable \\
\hline Behavioral reaction \\
When A is not present, I say that A is irresponsible \\
I console A \\
I directly tell A to be irresponsible \\
I forgive A \\
I punish A \\
I am kind to A \\
I express anger toward A
\end{tabular}

Note. When asking about the target in a second vignette, A was replaced by $\mathrm{B}$.

\subsection{Statistical Analysis}

R for Windows version 2.15.0 (R Development Core Team, 2012) and "anovakun version 4.6.2," an ANOVA function that runs on $\mathrm{R}$ software, were used for all statistical analyses. Structural equation modeling was conducted using R package lavaan (Yves, 2012). The analysis used the maximum-likelihood method of parameter estimation and, for the model estimation, we used the following goodness-of-fit indexes: CFI (comparative fit index), TLI (Tucker-Lewis Index), RMSEA (root mean square error of approximation), SRMR (standardized root mean square residual). CFI and TLI values close to 1 or at least greater than 0.95 indicate good fit. In contrast, RMSEA and SRMR values less than .05 are considered as good fit. The significance level for all analyses was set at alpha $=.05$.

\section{Results}

\subsection{Manipulation Check}

Some participants were excluded from the analyses after an initial inspection of the data, because they regarded the target as less responsible to his duty. More precisely, 70 participants who responded to manipulation checks assessing responsibility of the target with 1 or 2 at least 1 item were excluded from the following analyses.

\subsection{Descriptive Statistics}

Table 2 presents the means, standard deviations, and 95\% confidence intervals of mean for all variables in the analysis across the two conditions. Because there was no significant difference between sex or major (psychology major students and non-psychology major students) in all variables, all data are presented for the total population.

\subsection{Analysis}

First, the effect of the excuse and the difference between the situations were evaluated using 2 (excuse vs. no excuse) $\times 2$ (college scenario vs. workplace scenario) between-within mixed-model analysis of variances (ANOVAs). The first factor was a between-subjects factor and the other was a within-subjects factors. The dependent measures included the impression on the target and behavioral reaction to the target. 
Results of ANOVA on the total means obtained for the impression on target yielded a significant main effect of excuse, $F(1,272)=36.93, p<.001, \eta_{p}^{2}=0.12,95 \%$ CI [0.06, 0.19], and a significant main effect of situation, $F$ $(1,272)=32.94, p<.001, \eta_{p}^{2}=0.11[0.05,0.18]$. However, there were no significant interaction effects, $F$ $(1,272)=0.08, p=.078, \eta_{p}^{2}=0.0003[0.00,0.02]$. ANOVA on the total means obtained for the behavioral reaction to target indicated similar results as the means of impression score. Each of the main effects was significant but there was no significant interaction: For excuse, $F(1,272)=53.67, p<.001, \eta_{p}^{2}=0.16[0.09$, $0.24]$; for situation, $F(1,272)=10.08, p=.0017, \eta_{p}^{2}=0.04[0.01,0.09]$; and for excuse $\times$ situation interaction, $F$ $(1,272)=0.23, p=.063, \eta_{g}^{2}=0.0008[0.00,0.02]$. In sum, the ANOVA results revealed that on both impression score and behavioral reaction score, the target in the excuse condition was evaluated more positively than in the no excuse condition; in particular, the most positive evaluation was in the workplace scenario.

Table 2. Descriptive statistics for all variables in the analysis across the two conditions

\begin{tabular}{|c|c|c|c|c|c|c|}
\hline \multirow[b]{3}{*}{ Variable } & \multicolumn{3}{|c|}{ Excuse condition } & \multicolumn{3}{|c|}{ No excuse condition } \\
\hline & \multirow[b]{2}{*}{$M(S D)$} & \multicolumn{2}{|c|}{$95 \% \mathrm{CI}$} & \multirow[b]{2}{*}{$M(S D)$} & \multicolumn{2}{|c|}{$95 \% \mathrm{CI}$} \\
\hline & & $L L$ & $U L$ & & $L L$ & $U L$ \\
\hline Impression (College scenario) ${ }^{\mathrm{a}}$ & $33.51(6.84)$ & 32.47 & 34.56 & $29.16(5.88)$ & 28.02 & 30.30 \\
\hline Impression (Workplace scenario) ${ }^{\mathrm{a}}$ & $35.51(6.32)$ & 34.55 & 36.47 & $31.36(5.90)$ & 30.21 & 32.51 \\
\hline Behavioral response (College scenario) ${ }^{\mathrm{b}}$ & $23.61(4.74)$ & 22.89 & 24.33 & $20.36(3.68)$ & 19.65 & 21.08 \\
\hline Behavioral response (Workplace scenario) & $24.55(4.04)$ & 23.93 & 25.17 & $21.06(4.16)$ & 20.25 & 21.87 \\
\hline Uncontrollability & $5.14(1.50)$ & 4.91 & 5.36 & $5.06(1.51)$ & 4.76 & 5.35 \\
\hline
\end{tabular}

Note. $\mathrm{CI}=$ confidence interval; $L L=$ lower limit, $U L=$ upper limit.

${ }^{\text {a }}$ The possible range for item scores is 12 to 60 .

${ }^{\mathrm{b}}$ The possible range for item scores is 7 to 35 .

${ }^{\mathrm{c}}$ The possible range for item scores is 1 to 7 .

Finally, to examine the process in which people evaluate the excuse being made in this study, path analysis with manifest-variable using structural equation modeling was employed for the excuse condition samples. Intercorrelations among the variables are summarized in Table 3. The hypothetical model was developed based on the cognitive (attribution)-emotion-action model (Weiner, 1995). The model test of the college scenario suggested that the model fit the data well, $\chi^{2}(3)=221.04, p<.001(\mathrm{CFI}=.997$, TLI $=.991$, RMSEA $=.048$, SRMR $=.021)$. As shown in Figure 1, all paths were significant and the coefficients of determination for the impression score and for the behavioral reaction were as follows: $R^{2}=.02, R^{2}=.54$. Similarly, the model test of the workplace scenario was conducted. The result of SEM shows the model fit the data well, $\chi^{2}(3)=225.58, p$ $<.001(\mathrm{CFI}=1.00, \mathrm{TLI}=1.00, \mathrm{RMSEA}=0, \mathrm{SRMR}=.008)$. All paths were significant and each coefficient of determination were similar to those of the college scenario (impression score: $R^{2}=.02$; behavioral reaction: $R^{2}$ $=.55)$.

Table 3. Summary of intercorrelations for scores on the impression and behavioral response of each vignette in excuse condition $(n=169)$

\begin{tabular}{|c|c|c|c|c|c|c|c|}
\hline & & 1. & & 2. & & 3. & \\
\hline 1. & Impression & - & & .71 & $* * *$ & .24 & $* *$ \\
\hline 2. & Behavioral response & .74 & $* * *$ & - & & .17 & * \\
\hline 3. & Uncontrollability & .24 & $* *$ & .19 & * & - & \\
\hline
\end{tabular}

Note. Intercorrelations in the college scenario were presented below the diagonal, and intercorrelations in the workplace scenario were presented above the diagonal. ${ }^{*} p<.05,{ }^{* *} p<.01,{ }^{* * *} p<.001$ 


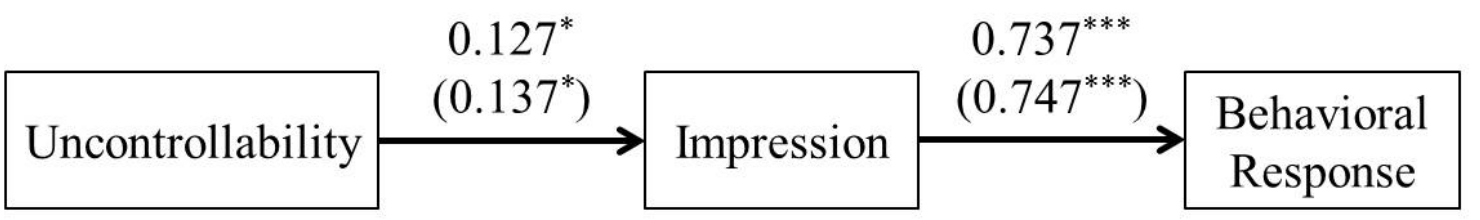

Figure 1. Relationship between causal attribution of uncontrollability on depressive disorder, impression on target, and behavioral response on target.

Note. All estimates were standardized. Numbers in parentheses show the estimates in the workplace scenario. ${ }^{*} p<.05,{ }^{* * *} p<.001$

\section{Discussion}

Since the late 1990s, Japanese psychiatrists have reported the appearance of MTD, which has different features to melancholic depression. Nevertheless, until now, few empirical studies have looked at the psychological aspects of MTD. The present study approached one of the distinctive features of MTD - "insisting on depression." In particular, we examined the interpersonal consequences of saying "I think I may have depressive disorder" in two different case vignettes and confirmed the process of evaluating that statement. Results indicated that the statement made by people who show no depressive symptoms seemed to be accepted as an excuse. Furthermore, consistent with the cognitive (attribution)-emotion-action model (Weiner, 1995), the more positive impression that observers have (e.g., likability, sincerity, or sympathy) toward the transgressor, the more they are motivated to react positively (e.g., forgiving, or taking care) to the transgressor. However, there were also two unexpected findings. First, the reactions of participants on the target person differed significantly in the situations. Second, in our results, attribution about the uncontrollability of depressive disorder did not account for a significant amount of variance in the impression on the transgressor. In the following section, we discuss some of the implications of these results while considering these unexpected findings.

In social predicaments, the impression on a transgressor who insisted on having depression was evaluated more positively than who did not; likewise, the motivated behavior was more positive for the target in the excuse condition than in the no excuse condition. Tyler and Feldman (2007) found that offering an invalid excuse did not disengage people from negative outcomes. Moreover, it might result in unfavorable character assessment or increase a judgment-maker's motivation to deliver a negative reaction. Hence, our results are interpreted as suggesting that insisting on having depression without any symptom functions as a valid excuse. These results seem to support what Japanese psychiatrists have noted on the basis of their clinical experiences: that people with MTD take advantage of depressive disorder in order to shift the responsibility and/or to excuse their inconvenient behavior (e.g., poor job performance, and the requirements from the social environment) (Nomura \& Hirakawa, 2009; Yoshino, 2009).

Conversely, the difference between the response in the college scenario and the response in the workplace scenario was unexpected. Because the study participants were undergraduates, we used those two scenarios in order to ensure the cross-validity of the results, although the MTD has become a subject of discussion in company organizations. Previous studies about interpersonal consequences of excuse-making manipulated together the contents of the excuse and the situation in which the excuse was made (Pontari et al., 2002; Tyler, \& Feldman, 2007) or presented multiple excuses in the same situation (Weiner, Folkes, Amirkhan, \& Verette, 1987). Thus, these different results among the situation are not well understood at this time. However, one can consider the possibility that participants assessed the fault in the college scenario (i.e., not doing the assignment) as more pernicious than the one in the workplace scenario (i.e., the absence without notice). As Blumstein et al. (1974) suggested, there appears to be a relationship between the perceived offensiveness of a violation and the offender's ascribed causation (i.e., controllability of the deed in question). Hence, comparing the consequences of excuse-making in multiple situations, controlling the offensiveness of the violations is needed.

Next, path analysis with manifest-variable using structural equation modeling demonstrated that a more positive impression of the excuse-maker was associated with more favorable reactions toward him. In light of this result, we may interpret that people react to the transgressor who insists on having depressive disorder in the same way as other cases of moral judgment. However, because the low coefficient of determination showed a small positive association between the impression on target and the causal attribution of uncontrollability about depressive disorder, it is still unclear what factors influenced on impression formation, despite these variables 
being significantly correlated. Accordingly, further study should be conducted to examine what factors determine a judgment maker's impression on the transgressor who insists on having depressive disorder. One possibility is that familiarity with mental illness (Holmes, Corrigan, Williams, Canar, \& Kubiak, 1999) has an effect on the impression towards the transgressor. A study on stigma of mental illness demonstrated that greater familiarity with mental illness was associated with feeling greater pity, less anger, and being more willing to help people with schizophrenia (Corrigan, Markowitz, Watson, Rowan, \& Kubiak, 2003). Hence, it is likely that familiarity with mental illness affects impression formation in the case of evaluating an excuse, such as insisting on depressive disorders.

Finally, in addition to the problems discussed above, two limitations of the present study must be considered. One limitation is that because this was an initial study about those insisting on depressive disorders being an excuse without any typical symptom of depression, the main focus of the study was to confirm whether at least the statement "I think I may have depressive disorder" functions as an excuse. Thus, the present study did not examine the differences among other types of excuses. Therefore, future study should compare multiple excuses, including insisting on depression, to examine the relative effects of each excuses, making it more possible to understand precisely the characteristics of insisting on depression, as well as the interpersonal aspects of depression.

The other limitation is as follows. Essentially, we have attempted to approach one of the controversial features of people with MTD. However, because the discussion about MTD is limited in its description of the variety of syndromes compromising MTD (Kato et al., 2011) and there is still no agreement about the common cognitive and behavioral features of MTD, we were unable to describe directly a protagonist in our vignette as a "typical" person with MTD. Instead, we excluded descriptions of symptoms of depression to differentiate from melancholic depression. It is hoped that further discussion will create a common understanding of the characteristics of MTD.

\section{Acknowledgments}

This work was supported by JSPS KAKENHI Grant Number 25380854. This experiment is based on a Master's thesis submitted by the first author under the supervision of the second author to the Graduate School of Literature and Social Sciences, Nihon University. Portions of this research were presented at the 55th Annual Meeting of the Japanese Society of Social Psychology in Aichi, Japan on November 2nd and 3rd, 2013.

\section{References}

Baumgardner, A. H. (1991). Claiming depressive symptoms as a self-handicap: A protective self-presentation strategy. Basic and Applied Social Psychology, 12, 97-113. http://dx.doi.org/10.1207/ s15324834basp1201_7

Baumgardner, A. H., Lake, E. A., \& Arkin, R. M. (1985). Claiming mood as a self-handicap: The influence of spoiled and unspoiled public identities. Personality and Social Psychology Bulletin, 11, 349-357. http://dx.doi.org/10.1177/0146167285114001

Berglas, S., \& Jones, E. E. (1978). Drug choice as a self-handicapping strategy in response to noncontingent success. Journal of Personality and Social Psychology, 36, 405-417. http://dx.doi.org/10.1037/ 0022-3514.36.4.405

Blumstein, P. W. et al. (1974). The honoring of accounts. American Sociological Review, 39, 551-566. http://dx.doi.org/10.2307/2094421

Braginsky, B. M., \& Braginsky, D. D. (1967). Schizophrenic patients in the psychiatric interview: An experimental study of their effectiveness at manipulation. Journal of Consulting Psychology, 31, 543-547. http://dx.doi.org/10.1037/h0021007

Corrigan, P., Markowitz, F. E., Watson, A., Rowan, D., \& Kubiak, M. A. (2003). An attribution model of public discrimination towards persons with mental illness. Journal of Health and Social Behavior, 44, 162-179. http://dx.doi.org/10.2307/1519806

Hayashi, K. (2001). 擬態うつ病 [Mimetic Depression]. Tokyo: Takarajima-shya.

Holmes, E. P., Corrigan, P. W., Williams, P., Canar, J., \& Kubiak, M. A. (1999). Changing attitudes about schizophrenia. Schizophrenia Bulletin, 25, 447-456. http://dx.doi.org/10.1093/oxfordjournals.schbul. a033392

Jones, E. E., \& Berglas, S. (1978). Control of attributions about the self through self-handicapping strategies: The appeal of alcohol and the role of underachievement. Personality and Social Psychology Bulletin, 4, 200-206. http://dx.doi.org/10.1177/014616727800400205

Kanba，S. (2011). 現代社会とうつ病 (1) 連載開始にあたり. [The modern society and depression (1)]. SAISHIN IGAKU, 66, 1046-1048. 
Kato, T. et al. (2011). Introducing the concept of modern depression in Japan: An international case vignette survey. Journal of Affective Disorders, 135, 66-76. http://dx.doi.org/10.1016/j.jad.2011.06.030

Matsuo, S. (2009). 「ディスチミア親和型うつ病」を通してみる現代うつ病医療 [Modern medical treatment for depression through "dysthymic type of depression”]. In S. Kanba, \& T. Kuroki. (Eds.), 現代 うつ病の臨床[Modern medical care for depression]. Osaka: Sogensha.

Nomura, S. (2008). 操作的診断により変化したうつ病の一般イメージ [A public image of depressive disorder changed by operational diagnosis]. Journal of Japanese Association of Psychiatric Hospitals, 27, 269-273.

Nomura, S., \& Hirakawa, H. (2009). MEET MEDICAL EXPERTS TALK 増加するうつ病: 今後の診療の姿 とは [Meet Medical Experts talk Incremental depression: A future vision of medical care]. Japanese Medical Journal, 4467, 34-41.

Peterson, C. et al. (1982). The attributional style questionnaire. Cognitive Therapy and Research, 6, 287-299. http://dx.doi.org/10.1007/BF01173577

Pontari, B. A., Schlenker, B. R., \& Christpher, A. N. (2002). Excuses and character: Identifying the problematic aspects of excuses. Journal of Social and Clinical Psychology, 21, 497-516. http://dx.doi.org/ $10.1521 /$ jscp.21.5.497.22621

R Development Core Team. (2012). R: A language and environment for statistical computing. Vienna, Austria: $\mathrm{R}$ foundation for statistical computing. Retrieved from http://www.R-project.org/

Schlenker, B. R. et al. (1994). The triangle model of responsibility. Psychological Review, 101, 632-652. http://dx.doi.org/10.1037/0033-295X.101.4.632

Schouten, P. G., \& Handelsman, M. M. (1987). Social basis of self-handicapping: The case of depression. Personality and Social Psychology Bulletin, 13, 103-110. http://dx.doi.org/10.1177/0146167287131010

Snyder, C. R., \& Higgins, R. L. (1988). Excuses: Their effective role in the negotiation of reality. Psychological Bulletin, 104, 23-35. http://dx.doi.org/10.1037/0033-2909.104.1.23

Snyder, C., \& Smith, T. (1981). Symptoms as self-handicapping strategies: The virtues of old wine in a new bottle. In G. Weary, \& H. L. Mirels (Eds.), Integrations of clinical and social psychology (pp. 104-127), New York: Oxford University Press.

Tarumi, S. (2005). うつ病の社会文化的試論: 特に「ディスチミア親和型うつ病」について [The “new” variant of depression: The dysthymic type]. Japanese Journal of Clinical Psychiatry, 34, 687-694.

Tarumi, S., \& Kanba, S. (2005). うつ病の社会文化的試論: 特に「ディスチミア親和型うつ病」について [The dysthymic type of depression: an essay on socio-cultural aspects of depression]. Japanese bulletin of social psychiatry, 13, 129-136.

Tedeschi, J. T., \& Norman, N. (1985). Social power, self-presentation, and the self. In B. R. Schlenker (Ed.), The self and social life (pp. 291-322). New York: McGraw-Hill.

Tyler, J. M., \& Feldman, R. S. (2007). The double-edged sword of excuses: When do they help, when do they hurt. Journal of Social and Clinical Psychology, 26, 659-688. http://dx.doi.org/10.1521/jscp.2007.26.6.659

Weiner, B. (1979). A theory of motivation for some classroom experiences. Journal of Educational Psychology, 71, 3-25. http://dx.doi.org/10.1037/0022-0663.71.1.3

Weiner, B. (1995). Judgments of responsibility: A foundation for a theory of social conduct. New York: The Guilford Press.

Weiner, B. (2006). Social motivation, justice, and the moral emotions: An attributional approach. Mahwah, NJ: Lawrence Erlbaum Associates.

Weiner, B., Amirkhan, J., Folkes, V. S., \& Verette, J. A. (1987). An attributional analysis of excuse giving: Studies of a naive theory of emotion. Journal of Personality and Social Psychology, 52, 316-324. http://dx.doi.org/10.1037/0022-3514.52.2.316

Yoshino, S. (2009). それってホントに「うつ」?: 間違いだらけの企業の「職場うつ」対策[Is it really "depressive disorder"?: The countermeasures against "working depression" in companies are full of mistakes]. Tokyo: Kodansya.

Yves, R. (2012). Lavaan: An r package for structural equation modeling. Journal of Statistical Software, 48, 1-36. Retrieved from http://www.jstatsoft.org/v48/i02/

\section{Notes}

Note 1. Tarumi (2005) suggested that the waning social order or social role disruption may cause MTD. For instance, in the 1970s, the occupational role was more dominant than currently, combined with a period of high economic growth in Japan. MTD might be influenced by a loss of such roles, as they are replaced by a kind of overprotected individualism which has become the framework within Japan (Tarumi \& Kanba, 2005). 
Furthermore, enlightenment regarding depressive disorders, as well as social change, might contribute to MTD. In Japan, health promotion regarding depression has increased (Kanba, 2011). As a result, the stigma of depression has reduced somewhat (Hayashi, 2001). Accordingly, the number of Japanese people who suspect that one has depressive disorder and voluntarily get check-ups at the hospital has increased (Kanba, 2011; Nomura \& Hirakawa, 2009). However, it seems that this is not solely positive; people who do not have clear/severe depressive symptoms, but who are convinced that they suffer from depressive disorder, have appeared (Nomura \& Hirakawa, 2009).

Note 2. Although the original model by Weiner (1995) included only affects as the component, which arose subsequent to causal inference, we put impression and affects together, because those were treated in parallel as a result of excusing behaviors (Weiner et al., 1987).

\section{Appendix}

\section{Appendix A}

Scenario in which a student participating in a group project failed to undertake the work assigned to him while all the other group members did.Student A attends a university in Tokyo. A group work project has been assigned in one of his classes, which requires Student A to work with a set of friends on a collaborative presentation. Student A's group decided to divide the work such that each member would research a topic under a certain section. Student A was assigned the section that he wanted. Each member was asked to report his or her findings 3 days later and then continue the project as a group. It was mentioned that the project would be jeopardized if even a single member of the group failed to carry out the assigned work. Therefore, all members promised to do what they were assigned so as not to let the others down. The members then dispersed.

When the group met again three days later, everyone had completed their research work except for Student A. When asked by the other members why he had not done so, he replied, "I could not do it, I think I may have depressive disorder".

Student A's speech and behavior suggest that he actually believes that he suffers from depression.

\section{Appendix B}

Scenario in which a student and part-time worker failed to turn up for work while all other staff members did.

Student B attends a university in Tokyo. He also works part time at a large chain izakaya (Japanese-style bar). The izakaya has recently grown in popularity. The shop is now packed with customers regularly, which means that the staff members are constantly busy.

Student B's was scheduled to come to work in 3 days' time. A number of parties had already been booked for that day, so the staff members were aware that it would be extremely busy. For this reason, Student B and the other staff members were told that they should do their best to come to work on that day. The staff conferred among themselves and agreed that the higher the number of people that come to work, the lighter the load will be Therefore, all staff members promised to do what they needed to not let the others down. Student B and the rest of the staff members then went home.

Three days later, everyone except Student B turned up for work. On a later day, Student B was asked by one of the staff members why he did not turn up for work. He replied, "I could not come, I think I may have depressive disorder".

Student B's speech and behavior suggest that he actually believes that he suffers from depression.

\section{Copyrights}

Copyright for this article is retained by the author(s), with first publication rights granted to the journal.

This is an open-access article distributed under the terms and conditions of the Creative Commons Attribution license (http://creativecommons.org/licenses/by/3.0/). 